\title{
Mechanically Stacked Solar Cells for Concentrator Photovoltaics
}

\author{
Ian Mathews ${ }^{1}{ }^{*}$, Donagh O'Mahony ${ }^{1}$, Weiwei $\mathrm{Yu}^{1}$, Declan Gordan ${ }^{2}$, Nicolas Cordero ${ }^{1}$, Brian Corbett ${ }^{1}$, and Alan \\ P. Morrison ${ }^{2,1}$ \\ ${ }^{\prime}$ Tyndall National Institute UCC, Lee Maltings, Prospect Row, Cork, Ireland \\ ${ }^{2}$ Department of Electrical and Electronic Engineering, University College Cork, Cork, Ireland
}

*Correspondence: ian.mathews@tyndall.ie, Tel: +353 21 4904177, Address: Tyndall National Institute, Lee Maltings, Prospect Row, Cork, Ireland

\begin{abstract}
The power output of dual-junction mechanically stacked solar cells comprising different sub-cell materials in a terrestrial concentrating photovoltaic module has been evaluated. The ideal bandgap combination of both cells in a stack was found using EtaOpt. A combination of $1.4 \mathrm{eV}$ and $0.7 \mathrm{eV}$ has been found to produce the highest photovoltaic conversion efficiency under the AM1.5 Direct Solar Spectrum with x500 concentration. As EtaOpt does not consider the absorption profile of solar cell materials; the practical power output per unit area of a dual junction mechanically stacked solar cell has been modelled considering the optical absorption co-efficients and thicknesses of the individual solar cells. The model considered a GaAs top cell and a $\mathrm{Ge}, \mathrm{GaSb}, \mathrm{Ga}_{0.47} \mathrm{In}_{0.53} \mathrm{As}$ or Si bottom cell. It was found that $\mathrm{GaSb}$ gives the highest power contribution as a bottom cell in a dual junction configuration followed by $\mathrm{Ge}$ and GaInAs. While the additional power provided by a Si bottom cell is less than these it remains a suitable candidate for a bottom cell owing to its lower cost.
\end{abstract}

\section{Keywords}

Mechanical Stack, GaAs, Photovoltaic, Concentration, Modelling

\section{Introduction}

Photovoltaic (Solar) energy is playing an increasingly significant role in meeting European and Worldwide targets for renewable power generation [1]. Monolithically-grown triple-junction III-V/Ge PV solar cells currently represent the state-of-the-art in terms of the highest sunlight to electricity conversion efficiencies achieved to date. Nevertheless, drawbacks associated with current matching, crystal lattice mismatch between optimum cell materials and cell interconnect (tunnel junction) reliability, particularly in the case of solar concentrator systems, are of some concern [2]. Mechanically stacked solar cells (MSSC) can overcome these issues [3], however, they present alternative challenges primarily due to the complexity of integration of the various sub-cells with minimal optical loss and at minimal cost. Currently the state of the art MSSC, using a spectral splitting approach, has reached a photovoltaic conversion efficiency of $38.5 \%$ under $\times 20$ concentration [4].

In this study the theoretical power performance of dualjunction mechanically stacked solar cells using the solar cell simulation program EtaOpt [5] is presented. The optimum multi-cell configuration was determined for use in a terrestrial concentrating (500 suns) photovoltaic system. An additional modelling approach was also developed to investigate the effect of the optical absorption properties and cell thickness on MSSC performance. This modelling approach was adapted from those already used to investigate the effect of cell thickness on power output from monolithic multi-junction solar cells $[6,7]$. These two modelling approaches were used to evaluate the power output of MSSCs incorporating GaAs single junction top-cells with Ge, GaSb or $\mathrm{Ga}_{0.47} \operatorname{In}_{0.53}$ As (GaInAs) bottom cells.

\section{Theoretical Modelling a) Bandgap Selection (EtaOpt)}

The choice of bandgap for both solar cells in a dual junction mechanical stack will determine the likely power output from the device. The detailed balance limit of efficiency [8] is commonly used to evaluate the potential power output of solar cells. This method assumes a solar cell behaves according to the one-diode model and considers radiative recombination as the only loss mechanism i.e. an ideal solar cell with no resistive, thermal or optical losses which are highly dependent on cell structure and design. EtaOpt is a free software program available from the Fraunhofer Institute [5] which uses the detail balance limit of efficiency to compare the performance of various bandgap arrangements in single or multi-junction solar cells. EtaOpt also makes a number of additional assumptions about the solar cells:

- All photons with $\mathrm{E}>\mathrm{Eg}$ are absorbed

- Each absorbed photon creates an electron-hole pair

The first model considered was a dual junction mechanical stack. Figure 1 is a plot of the expected photovoltaic conversion efficiency of this stack as a function of top and bottom cell bandgaps. The bandgap arrangement is illuminated by the AM1.5d (direct) spectrum under a concentration of 500 suns. The p-n junction temperatures were held constant at $300 \mathrm{~K}$. The plot shows GaAs $(1.41 \mathrm{eV})$ to be the ideal top cell in a dual junction mechanically stacked solar cell with a bandgap of $0.7 \mathrm{eV}$ being ideal for the bottom solar cell. This corresponds closely to a number of candidate materials namely $\mathrm{Ge}, \mathrm{GaSb}$ and GaInAs which have corresponding bandgaps of $0.67 \mathrm{eV}, 0.72 \mathrm{eV}$ and $0.75 \mathrm{eV}$ respectively. 


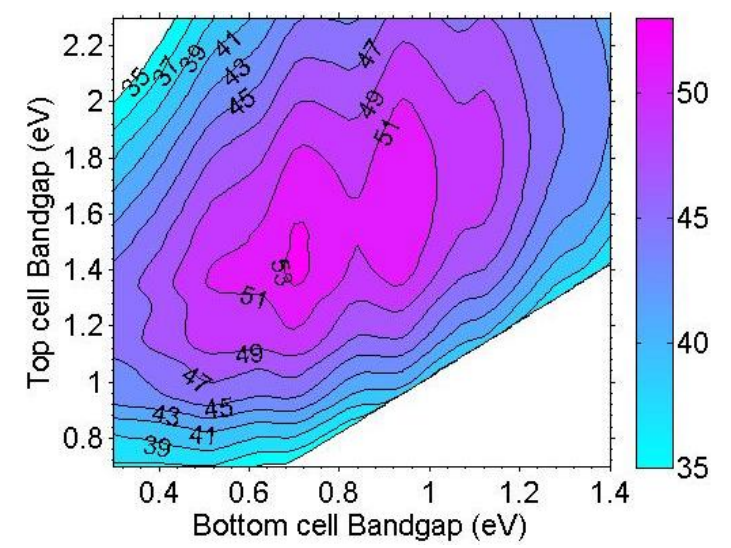

Figure 1: Photovoltaic conversion efficiency (\%) as a function of bandgap for an ideal dual-junction mechanical stack. Model conditions: AM1.5d, $x 500$ suns, $T=300 \mathrm{~K}$

\section{b) Absorption modelling}

While EtaOpt is a useful tool for determining the optimum band gap configuration for multi-junction solar cells; it's treatment of power losses is inadequate to determine the likely power output of individual solar cells in a stack. Modelling of a mechanically stacked solar cell was carried out using the material properties of $\mathrm{GaAs}, \mathrm{Si}, \mathrm{Ge}, \mathrm{GaSb}$ and InGaAs. The model is based on the one-dimensional semiconductor transport properties of each material and its absorption profile. The thicknesses of both solar cells in a dual junction mechanical stack were varied in order to investigate the effect of material thickness on the power produced by the complete stack.

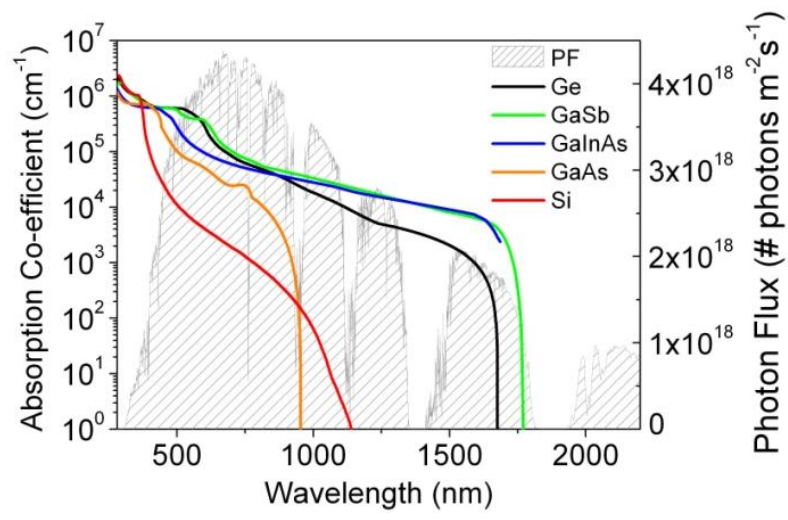

Figure 2: The absorption co-efficient versus wavelength for the candidate materials [11-13]: the AM1.5d solar spectrum is also shown.

The ideal diode equations for Photovoltaics were used to determine electrical performance of solar cells in a mechanical stack. The light generated current per unit area $\left(J_{L}\right)$ in a cell was determined using the AM1.5 Direct Solar Spectrum from the ASTM G-173-03 reference standard [9] as used in terrestrial concentrating PV systems. The photon flux $\left(P F(\lambda)\right.$, \# photons $\left.\mathrm{m}^{-2} \mathrm{~s}^{-1}\right)$ incident on a solar cell was determined using Equation 1 where $I o$ is the power $\left(\mathrm{W} \mathrm{m}^{-2} \mathrm{~nm}^{-1}\right)$ of the AM1.5 Direct Solar spectrum at wavelength $\lambda(\mathrm{nm})$.

$$
P F(\lambda)=\frac{I_{o}}{h c / \lambda} \Delta \lambda
$$

While EtaOpt assumes each incident photon with energy greater than the bandgap of the solar cell material is absorbed, the absorption profiles and thicknesses of the individual solar cells in a mechanical stack have been used to determine $J_{L}$. The absorption profiles given in Figure 2 were collected from various sources [10-12]. The light generated current per unit area, $J_{L}$, was taken as the number of photons absorbed across the entire thickness of the solar cell where losses due to grid shading and reflection were ignored as in Equation 2. It was assumed each photon absorbed with energy greater than the material bandgap $\left(E_{g}\right)$ created one electron-hole pair. Those photons absorbed with energy less than the bandgap were assumed not to contribute an electron-hole pair to the light generated current.

$$
J_{L}=\int_{\lambda=280 \mathrm{~nm}}^{\lambda=2500 \mathrm{~nm}} q P F(\lambda)\left(1-e^{-\alpha(\lambda) x}\right) \Delta \lambda
$$

The ideal diode equation (3) was used to determine the IV characteristics of a solar cell. A diode ideality of 1 was assumed with no series or shunt resistance losses considered.

$$
J(V)=J_{o}\left(e^{q V / k T}-1\right)-J_{L}
$$

The reverse saturation current density per unit area (4), $J_{o}$, was calculated as the sum of the contribution of the $\mathrm{n}$ - and p-type layers assuming uniform doping. Surface recombination has been ignored as it is dependent on the passivation used in the cell design which will vary greatly with mechanical stacking procedure.

$$
J_{o}=q n_{i}^{2}\left(\frac{D_{e}}{N_{A} L_{e}}+\frac{D_{h}}{N_{D} L_{h}}\right)
$$

The intrinsic carrier concentration $\left(\mathrm{n}_{\mathrm{i}}\right)$ is calculated in the usual way using Equations 5 \& 6:

$$
\begin{gathered}
n_{i}^{2}=N_{c} N_{v} e^{\left(-\frac{E g}{k T}\right)} \\
n_{i}^{2}=4 M_{c} M_{v}\left(\frac{2 \pi k T}{h^{2}}\right)^{3}\left(m_{e}^{*} m_{h}^{*}\right)^{3 / 2} e^{\left(-\frac{E g}{k T}\right)}
\end{gathered}
$$

The minority carrier diffusion constants $\left(D_{e}, D_{h}\right)$ are calculated using the Einstein relationship (7).

$$
D_{e}=\frac{k T \mu_{e}}{q} \text { and } D_{h}=\frac{k T \mu_{h}}{q}
$$

The electron and hole minority carrier diffusion lengths $\left(L_{e}, L_{h}\right)$ are given by $L_{e}=\sqrt{D_{e} \tau_{e}}$ and $L_{h}=\sqrt{D_{h} \tau_{h}}$ where the minority carrier mobilities $\left(\mu_{\mathrm{e}}, \mu_{\mathrm{h}}\right)$ and minority carrier lifetimes $\left(\tau_{e}, \tau_{h}\right)$ are taken from the literature [13][18].

The individual solar cells in a mechanical stack are connected in parallel allowing separate load control of each cell. Therefore the maximum power output per unit area of the stack is the sum of the maximum power output per unit area of the individual solar cells. This is found by differentiating the power output function of a solar cell and setting it to zero (8).

$$
P_{\text {out }}=J V \quad P_{\text {max }} \text { when } \frac{d(J V)}{d J}=0
$$

The photovoltaic conversion efficiency, $\eta$, is equal to $\mathrm{P}_{\text {in }} / \mathrm{P}_{\text {out }}$ where in this case the incident power of the AM1.5d spectrum is $1000 \mathrm{~W} / \mathrm{m}^{2}$. 
The theory was used to build a model based on the mechanically stacked solar cell structure given in Figure 3 . The model considered a GaAs top cell and a bottom solar cell of $\mathrm{Si}, \mathrm{Ge}, \mathrm{GaInAs}$ or GaSb. Reflection losses from the top surface of each cell or at the interface between the cells were ignored. The solar spectrum incident on the top solar cell, $I_{o}$, is the AM1.5d solar spectrum witnessed in concentrating photovoltaic systems. The spectrum incident on the bottom solar cell, $I_{t}$, is a modified version of $I_{o}$ where account has been taken of that portion of the spectrum absorbed in the GaAs solar cell as shown in Equation 9.

$$
I_{t}(\lambda)=I_{o}(\lambda) e^{-\alpha(\lambda) d}
$$

where $d(\mathrm{~cm})$ is the thickness of the top GaAs cell. $I_{t}$ now replaces $I_{o}$ in Equation 1. All other calculations for the bottom cell are the same.

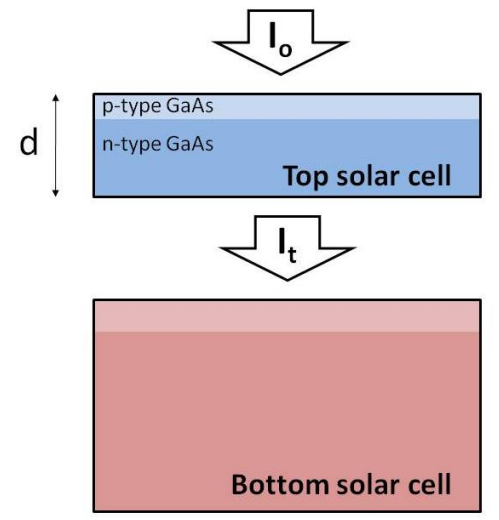

Figure 3: The mechanically stacked solar cell structure

The properties of the bottom cells reported are based on the best performing bottom cells produced by other groups for mechanical stacked solar cells [17], [19], [20] while the top GaAs solar cell is based on those being produced within the Tyndall National Institute. The material properties used are given in Table 1.

Table 1: Semiconductor material properties [14]-[19]

\begin{tabular}{|l|c|c|c|c|c|}
\hline & GaAs & Ge & GaSb & InGaAs & Si \\
\hline Type & p on $n$ & $n$ on $p$ & p on $n$ & $n$ on $p$ & $n$ on $p$ \\
\hline $\mathbf{E}_{\mathbf{g}}(\mathbf{e V})$ & 1.41 & 0.67 & 0.72 & 0.75 & 1.1 \\
\hline $\mathbf{N}_{\mathbf{A}}\left(\mathbf{c m}^{-3}\right)$ & $5 \times 10^{18}$ & $1 \times 10^{19}$ & $1 \times 10^{20}$ & $4 \times 10^{17}$ & $1 \times 10^{20}$ \\
\hline $\mathbf{N}_{\mathbf{D}}\left(\mathbf{c m}^{-3}\right)$ & $5 \times 10^{17}$ & $1 \times 10^{17}$ & $4 \times 10^{17}$ & $1 \times 10^{18}$ & $1 \times 10^{15}$ \\
\hline $\mathbf{n}_{\mathbf{i}}\left(\mathbf{c m}^{-3)}\right.$ & $2 \times 10^{6}$ & $2 \times 10^{13}$ & $1.5 \times 10^{12}$ & $6.3 \times 10^{11}$ & $1 \times 10^{10}$ \\
\hline $\begin{array}{l}\boldsymbol{\mu}_{\mathbf{e}}\left(\mathbf{c m}^{\mathbf{2}}\right. \\
\left.\mathbf{V}^{-1} \mathbf{s}^{-1}\right)\end{array}$ & 1200 & 2200 & 1500 & 200 & 650 \\
\hline $\begin{array}{l}\boldsymbol{\mu}_{\mathbf{h}}\left(\mathbf{c m}^{\mathbf{2}}\right. \\
\left.\mathbf{V}^{-1} \mathbf{s}^{-1}\right)\end{array}$ & 250 & 800 & 650 & 425 & 150 \\
\hline$\tau_{\mathbf{e}}(\boldsymbol{\mu s})$ & 0.0025 & 300 & 0.01 & 0.003 & 80 \\
\hline$\tau_{\mathbf{h}}(\boldsymbol{\mu} \mathbf{s})$ & 0.07 & 300 & 0.6 & 0.012 & 0.0007 \\
\hline
\end{tabular}

One method of producing Ge solar cells for mechanically stacked solar cells is spin-on-dopant diffusion [20]. This method allows for the production of thin Ge cells if a thin starting substrate is used.

The performance of a Ge solar cell under a GaAs top cell as a function of Ge layer thickness was modelled. Due to the longer diffusion lengths in Ge the thickness was varied from $1 \mu \mathrm{m}$ to $175 \mu \mathrm{m}$. Figure 5 shows the expected power output of a GaAs-Ge mechanically stacked solar cell as a function of top and bottom cell thicknesses. It shows a relatively thin layer of $\mathrm{Ge}(<10 \mu \mathrm{m})$ provides most of the additional benefit possible from stacking a Ge bottom cell. Ge solar cells of greater than $10 \mu \mathrm{m}$ thickness can provide a boost of $5-6 \mathrm{~mW} / \mathrm{cm}^{2}$ to a GaAs-based MSSC.

GaAs top cell

Figure 4 is a plot of GaAs solar cell electrical a direct-bandgap semiconductor which strongly absorbs absorbed within the first $5 \mu \mathrm{m}$ of the device. A GaAs cell thickness greater than this provides little additional power output from the device.

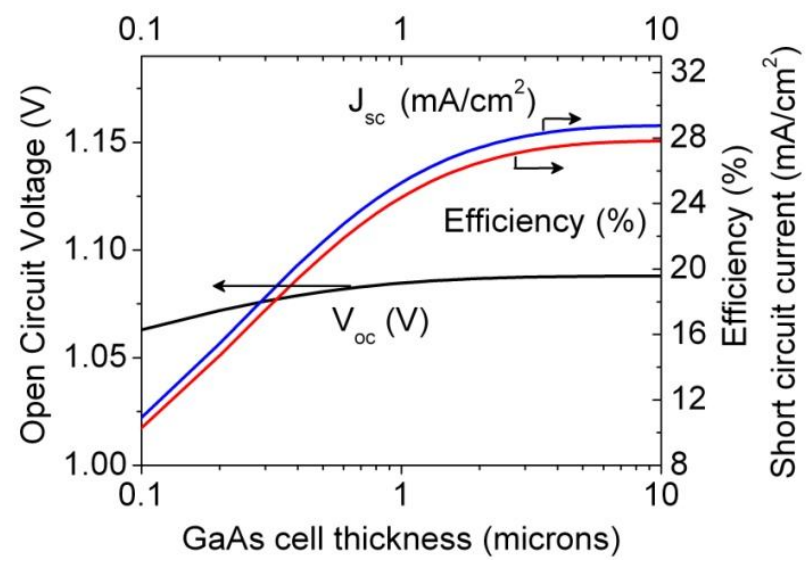

Figure 4: GaAs solar cell electrical characteristics as a function

In a mechanical stack; top cells transparent to photon wavelengths greater than their bandgap are desirable [19] cell. The thickness of a solar cell has a significant bearing on its transparency. A wide range of GaAs solar cell thicknesses are possible from thin epitaxial lift-off cells
[21] to those attached to substrates increasing in thickness to a maximum of $350 \mu \mathrm{m}$. The following sections outline the performance of a mechanical stack versus top and bottom cell thickness and material. The thickness of the of sub-bandgap absorption on the short circuit current produced in the top cell does not exceed that of a $10 \mu \mathrm{m}$ layer. 


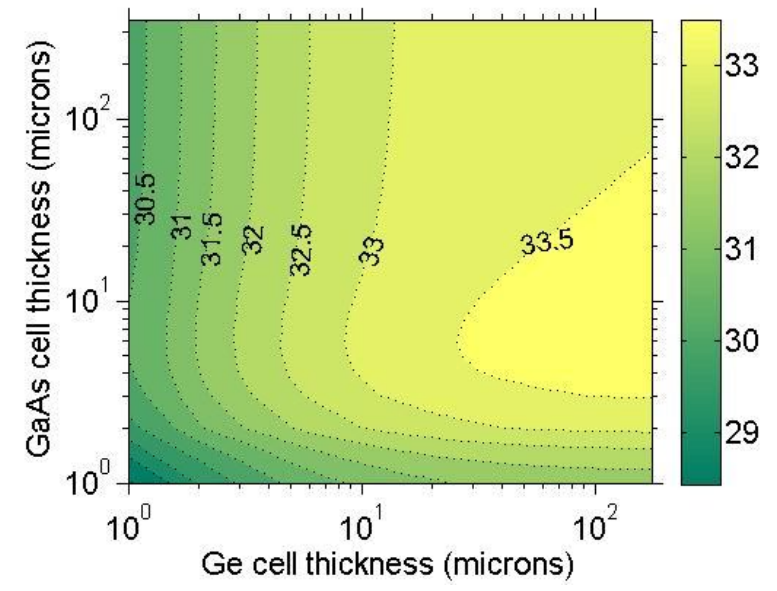

Figure 5: GaAs-Ge mechanically stacked solar cell power output $\left(\mathrm{mW} / \mathrm{cm}^{2}\right)$ as a function of layer thickness at $\mathrm{T}=300 \mathrm{~K}, 1000$ $\mathrm{W} / \mathrm{m}^{2} \mathrm{AM} 1.5 \mathrm{~d}$

With a top GaAs cell thickness of $5 \mu \mathrm{m}$ a short circuit density of $20 \mathrm{~mA} / \mathrm{cm}^{2}$ can be achieved in a Ge bottom cell of $10 \mu \mathrm{m}$ thickness (Figure 6). Increasing the Ge cell thickness to $175 \mu \mathrm{m}$ will provide a short circuit current density of $23 \mathrm{~mA} / \mathrm{cm}^{2}$ but this incurs a significant extra material cost. The limiting factor in Ge cells are the low values of open circuit voltage achievable compared to GaSb. Some groups are looking to overcome high recombination rates in $\mathrm{Ge}$ solar cells with passivation techniques [15]. Using thin Ge cells as the bottom device in an MSSC could lead to a reduction in the cost of multijunction solar cells.

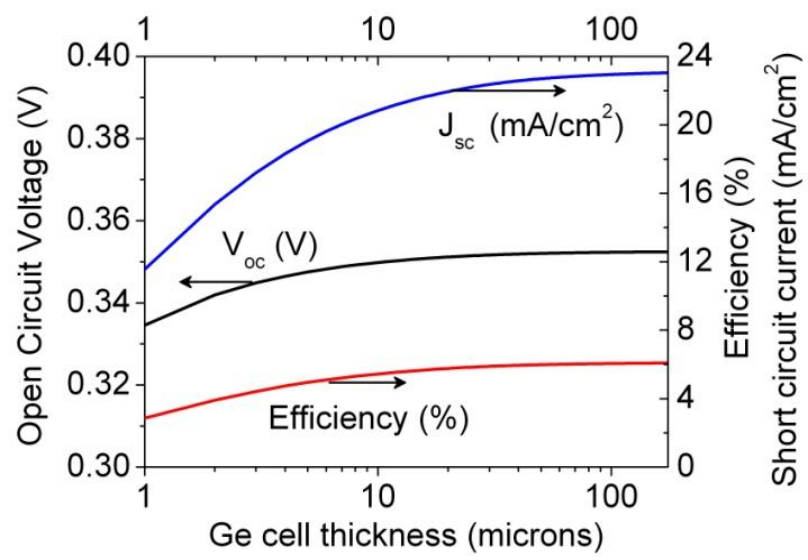

Figure 6: Ge solar cell electrical characteristics (stacked under a $5 \mu \mathrm{m} \mathrm{GaAs}$ top cell) as a function of layer thickness at $\mathrm{T}=300$

$$
\mathrm{K}, 1000 \mathrm{~W} / \mathrm{m}^{2} \mathrm{AM} 1.5 \mathrm{~d}
$$

\section{GaAs-GaSb MSSC}

The power output from a GaAs-GaSb mechanically stacked solar is higher than the other combinations considered in this paper (Figure 7).

$\mathrm{GaSb}$ is a direct bandgap semiconductor and thin layers produce high short circuit current densities. A GaSb solar cell with a thickness of $5 \mu \mathrm{m}$ can achieve a short circuit current density of $24 \mathrm{~mA} / \mathrm{cm}^{2}$ (Figure 8). The Open Circuit Voltages for GaSb are higher than those of Ge and GaInAs. When combined, a power output of $>35$ $\mathrm{mW} / \mathrm{cm}^{2}$ is possible for a GaAs-GaSb mechanically stacked solar cell under one-sun conditions.
GaSb solar cells are produced by Zinc diffusion doping processes [19]. As with $\mathrm{Ge}$ if a thin substrate is used a significant cost saving can be made.

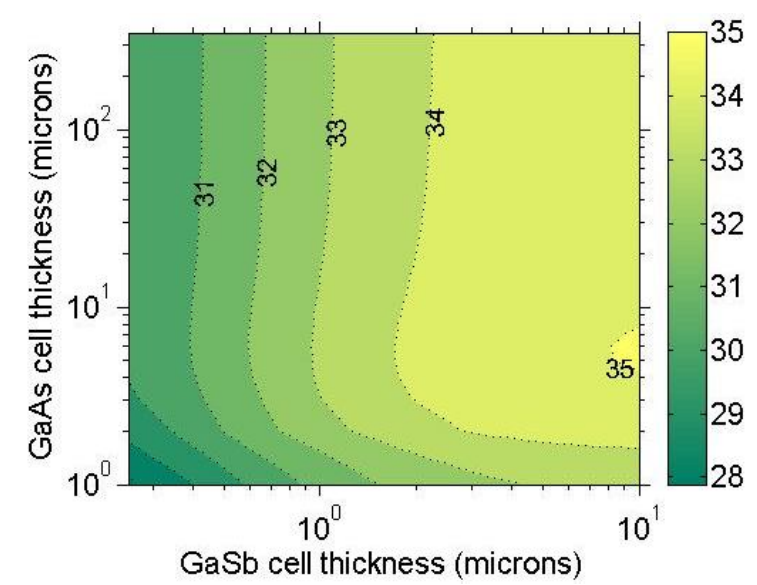

Figure 7: GaAs-GaSb mechanically stacked solar cell power output $\left(\mathrm{mW} / \mathrm{cm}^{2}\right)$ as a function of layer thickness at $\mathrm{T}=300 \mathrm{~K}$, $1000 \mathrm{~W} / \mathrm{m}^{2}$ AM $1.5 \mathrm{~d}$

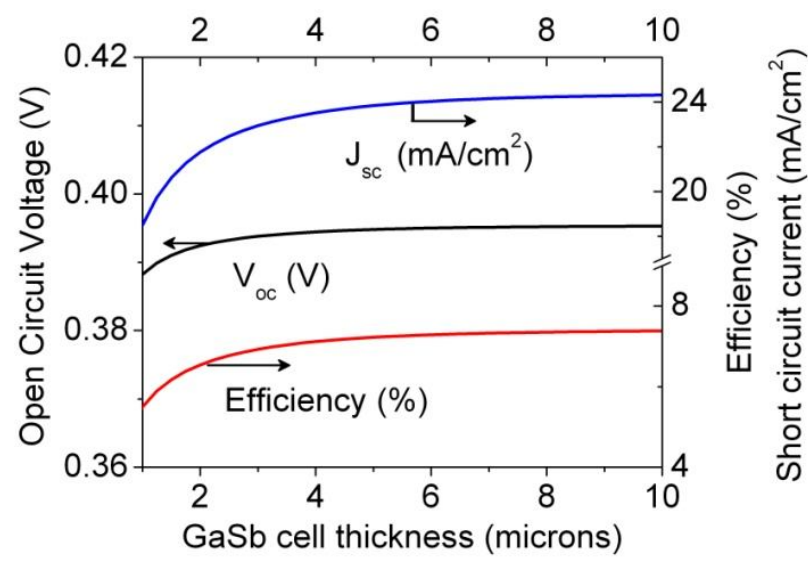

Figure 8: GaSb solar cell electrical characteristics (stacked under a $5 \mu \mathrm{m} \mathrm{GaAs}$ top cell) as a function of layer thickness at $\mathrm{T}=300$ $\mathrm{K}, 1000 \mathrm{~W} / \mathrm{m}^{2} \mathrm{AM} 1.5 \mathrm{~d}$

\section{GaAs-GaInAs MSSC}

GaInAs solar cells are grown epitaxially on InP substrates. The active layers (emitter and base) of such cells are less than $10 \mu \mathrm{m}$ thick.

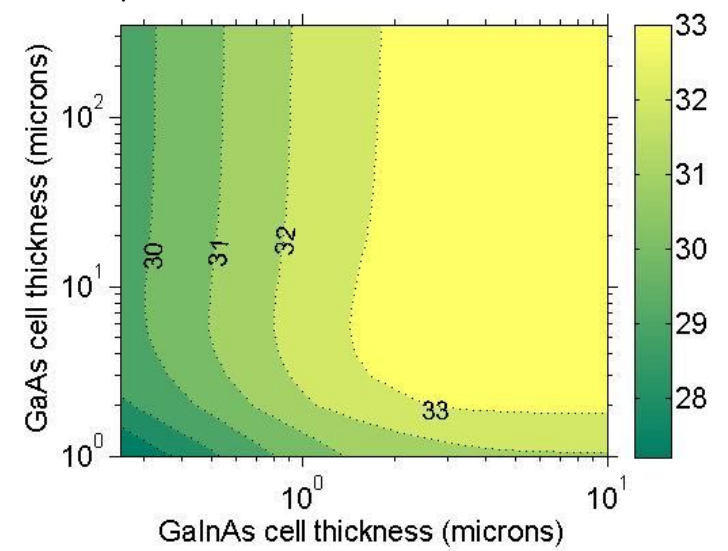

Figure 9: GaAs-GaInAs mechanically stacked solar cell power output $\left(\mathrm{mW} / \mathrm{cm}^{2}\right)$ as a function of layer thickness at $\mathrm{T}=300 \mathrm{~K}$, $1000 \mathrm{~W} / \mathrm{m}^{2}$ AM1.5d 
The performance of a GaInAs solar cell with active layers less than this thickness was modelled. It was assumed any absorption in the InP substrate does not contribute to the light generated current in the device.

It is clear from Figures $9 \& 10$ that a GaInAs solar cell stacked under a GaAs top cell can provide a significant boost to device performance. A power output of 5-6 $\mathrm{mW} / \mathrm{cm}^{2}$ can be achieved in the GaInAs device under a $\mathrm{GaAs}$ cell of $5 \mu \mathrm{m}$ thickness. However the production of thin, low-cost GaInAs cells requires the use of epitaxial lift-off techniques or thin InP substrates. InP-on-Insulator substrates have been produced [22] and may lead to low cost GaInAs solar cells.

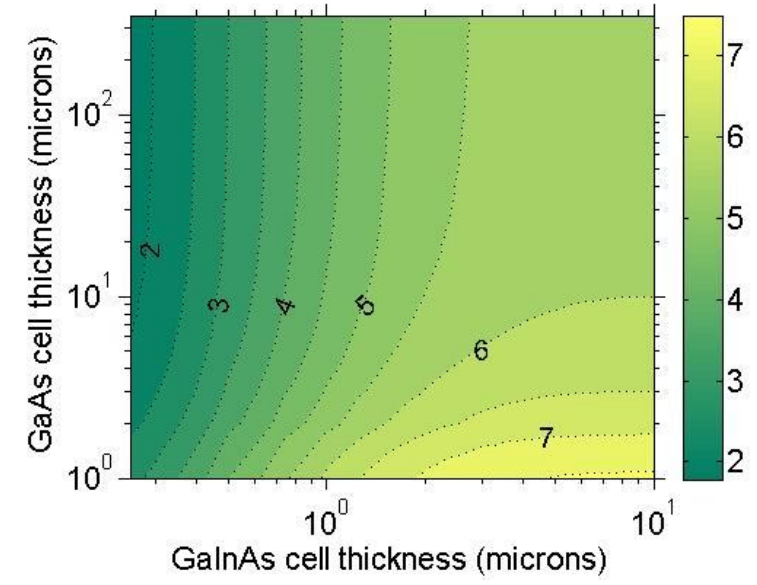

Figure 10: Power output $\left(\mathrm{mW} / \mathrm{cm}^{2}\right)$ from a GaInAs solar cell stacked under a GaAs top cell as a function of layer thicknesses at $\mathrm{T}=300 \mathrm{~K}, 1000 \mathrm{~W} / \mathrm{m}^{2} \mathrm{AM} 1.5 \mathrm{~d}$

GaAs-Si MSSC

As shown in Figure 4; $\mathrm{Si}$ weakly absorbs photons of wavelengths greater than $880 \mathrm{~nm}$. This results in low short circuit current densities for $\mathrm{Si}$ solar cells in a mechanical stack with GaAs top cells. A relatively thick Si cell of greater than $100 \mu \mathrm{m}$ is required before the $\mathrm{Si}$ cell in a stack provides much additional power to the device (Figure 11).

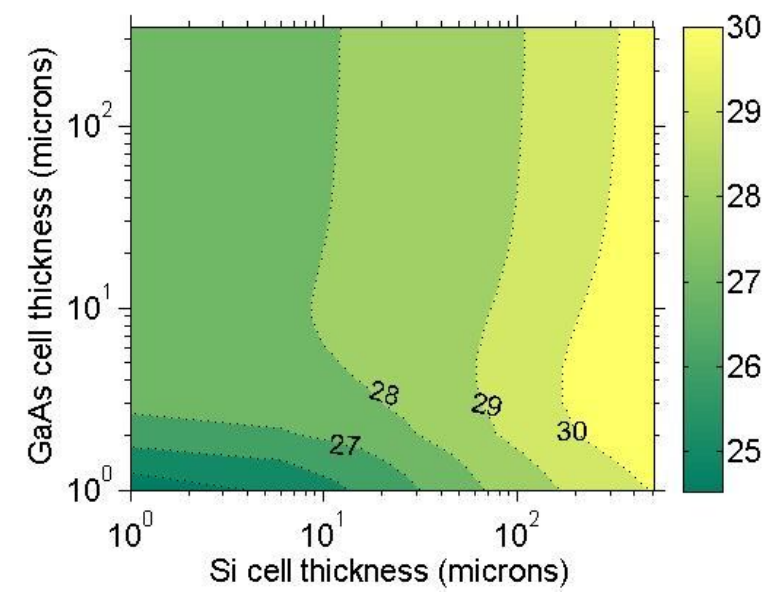

Figure 11: GaAs-Si mechanically stacked solar cell power output $\left(\mathrm{mW} / \mathrm{cm}^{2}\right)$ as a function of layer thickness at $\mathrm{T}=300 \mathrm{~K}, 1000$

$$
\mathrm{W} / \mathrm{m}^{2} \mathrm{AM} 1.5 \mathrm{~d}
$$

Under a GaAs top cell with a thickness of $5 \mu \mathrm{m}$; a $300 \mu \mathrm{m}$ $\mathrm{Si}$ solar cell will only provide an additional power output of $3 \mathrm{~mW} / \mathrm{cm}^{2}$ (Figure 12). However Si solar cells are cheaper to produce than others considered in this paper and a lower additional power output does not preclude their use in GaAs based MSSCs.

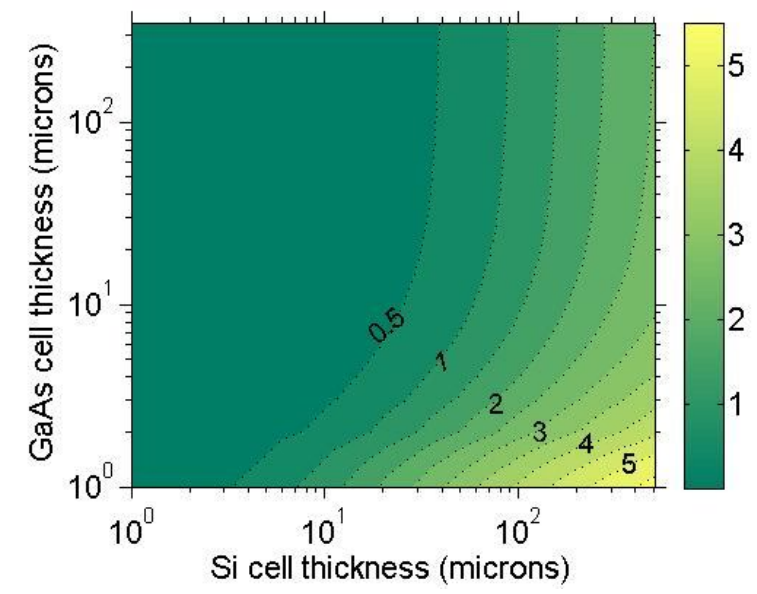

Figure 12: Power output $\left(\mathrm{mW} / \mathrm{cm}^{2}\right)$ from a Si solar cell stacked under a GaAs top cell as a function of layer thicknesses at $\mathrm{T}=$ $300 \mathrm{~K}, 1000 \mathrm{~W} / \mathrm{m}^{2} \mathrm{AM} 1.5 \mathrm{~d}$

\section{Conclusion}

The power output of a dual-junction mechanically stacked solar cell has been optimised for different sub-cell materials. A bandgap combination of $1.4 \mathrm{eV}$ and $0.7 \mathrm{eV}$ was found to produce the highest photovoltaic conversion efficiency under the AM1.5 Direct Solar Spectrum with x500 concentration by EtaOpt.

Modelling of the absorption profile and thicknesses of solar cells found a GaAs top solar cell thickness of 3-10 $\mu \mathrm{m}$ is the optimum in a dual junction stack as it balances the need for a high power output from the top cell with the need to be transparent to sub-bandgap photons.

The use of direct bandgap semiconductor materials such as $\mathrm{GaSb}$ and $\mathrm{InGaAs}$ are ideal for bottom cells in mechanically stacked solar cells. They provide an additional power output of 7 and $6 \mathrm{~mW} / \mathrm{cm}^{2}$ respectively, under an optimised GaAs top cell at one-sun conditions. However the cost of these materials may restrict their use to high concentration systems.

Using a Si solar cell as the bottom junction will result in a lower power output of $30 \mathrm{~mW} / \mathrm{cm}^{2}$ for the GaAs-Si stack. The costs of Si solar cells are lower than the other bottom cell materials considered in this study (Table 2).

Thin layers of $\mathrm{Ge}$ are the most suitable choice for bottom solar cells in GaAs based MSSCs. They combine the higher performance of direct bandgap materials but Ge substrates are cheaper than GaSb or InP substrates.

Table 2: Indicative cost of semiconductor wafer normalised to Si

\begin{tabular}{|c|c|c|c|}
\hline Si & Ge & InP & GaSb \\
\hline 1 & $\mathrm{x} 4$ & $\mathrm{x} 8$ & $\mathrm{x} 10$ \\
\hline
\end{tabular}

\section{List of Symbols}

$q \quad$ Electronic charge 
h Planck's constant

c Speed of light

$k \quad$ Boltzmann's constant

$T \quad$ Temperature

$\alpha(\lambda) \quad$ Absorption co-efficient of material

$N_{c} N_{v} \quad$ Density of states in the conduction, valence band

$M_{c} M_{v}$ Number of equivalent minima in the conduction, valence band

$m_{e} * m_{h} *$ Effective mass of electrons, holes

\section{Acknowledgement}

This work has been supported by Enterprise Ireland and the European Regional Development Fund

\section{References}

[1] "A vision for Photovoltaic technology", EU Commission Directorate for General Research, 2005

[2] K. Jandieri, S. D. Baranovskii, W. Stolz, F. Gebhard, W. Guter, M. Hermle, and A. W. Bett,

"Fluctuations of the peak current of tunnel diodes in multijunction solar cells", Journal of Physics D:

Applied Physics, 42(15):155101, 2009.

[3] G. Flamand, L. Zhao, Y. Mols, J. van der Heide, and J. Poortmans, "Development of mechanically

stacked Multi-Junction solar cells applying thin, one-side contacted III-V cells", Proc. of 24th European

Photovoltaic Solar Energy Conference, 21-25 September 2009,

Hamburg, Germany, pages 126 - 129, 2009.

[4] J.D. McCambridge et al., "Compact spectrum splitting photovoltaic module with high efficiency", Progress in Photovoltaics: Research and Applications, (published on-line on 24 September 2010).

[5] G. Letay and A. W. Bett, "EtaOpt - a program for calculating limiting efficiency and optimum bandgap structure for multibandgap solar cells and TPV cells", Proc. 17th EU-PVSEC Munich, 2001.

[6] S.R. Kurtz, P. Faine, J.M Olson, "Modeling of two-junction, series connected tandem solar cells using top-cell thickness as an adjustable parameter" Journal of Applied Physics, 1990, Vol. 68, 4, pp. 1890-1895.

[7] L. Hsu, W. Walukiewcz, "Modeling of InGaN/Si tandem solar cells", Journal of Applied Physics, 2008, Vol. 104, 2, 024507 .

[8] W. Shockley and H.J. Queisser, "Detailed balance limit of efficiency of p-n junction solar cells, Appl. Phys., Vol. 32, pp. 510-519, 1961.

[9] NREL (http://rredc.nrel.gov/solar/spectra/am1.5/).

[10] S. Adachi, Physical Properties of III-Y Semiconductor compounds, John Wiley and Sons, New York, 1992.

[11] D. Martin and C. Algora, "Key issues for an accurate modelling of GaSb TPV converters" Proc. of $5^{\text {th }}$

Thermophotovoltaic Generation of Electricity, 2003, Vol. 653, pp 442-51.

[12] PC1D,

(http://www.pv.unsw.edu.au/links/products/pc1d.asp).
[13] M.R Brozel, G.E. Stillman, Properties of Gallium Arsenide, INSPEC, London, (1996).

[14] M.B. Prince, "Drift Mobilities in Semiconductors. I. Germanium”, Physical Review, 1953, Vol. 92, 3, pp. 681-687.

[15] N.E. Posthuma, G. Flamand, W. Geens, J. Poortmans, "Surface passivation for germanium photovoltaic cells", Solar Energy Materials \& Solar Cells, 2005, 88, pp. 37-45.

[16] D. Martin and C. Algora, "Temperature-dependent GaSb material parameters for reliable thermophotovoltaic cell modelling", Semicond. Sci. Technology, 2004, 19, 8, pp.10401052.

[17] H. Matsubara, T. Tanabe, A. Moto, Y. Mine, S. Takagishi, "Over 27\% efficiency GaAs/InGaAs mechanically stacked solar cell”, Solar Energy Materials and Solar Cells, Vol. 50, pp. 177184.

[18] M.B. Prince, "Drift Mobilities in Semiconductors. II. Silicon”, Physical Review, 1954, Vol. 93, 6, pp. 1204-1206.

[19] M.Z. Shvarts, P.Y. Gazaryan, N.A. Kaluzhniy, V.P. Khvostikov, V.M. Lantratov, S.A. Mintairov, S.V. Sorokina, N.K. Timoshina, "InGaP/GaAs-GaSb and InGaP/GaAs/GeInGaAsSb hybrid monolithic/stacked tandem concentrator solar cells" Proc. of $21^{\text {st }}$ EUPVSEC, 2006.

[20] N.E. Posthuma, J. van der Heide, G. Flamand, J. Poortmans, "Emitter Formation and Contact Realization by Diffusion for Germanium Photovoltaic Device", IEEE Transactions on Electron Devices, Vol. 54, 5, pp. 1210-1215.

[21] G.J. Bauhuis, P. Mulder, E.J. Haverkamp, J.C.C.M. Huijben, J.J. Schermer, " $26.1 \%$ thin-film GaAs solar cell using epitaxial lift-off", Solar Energy Materials and Solar Cells, Vol. 93, 9, pp. 1488-1491.

[22] J.M. Zahler, K. Tanabe, C. Ladous, T. Pinnington, F.D. Newman, H.A. Atwater, "High efficiency InGaAs solar cells on Si by InP layer transfer", Applied Physics Letters, 2007, 91. 